Earnings of Junior and Senior Hospital Staff

SIR,-It is now widely recognized that extraduty payment can and frequently does enhance a senior registrar's salary above the basic rate for a consultant. In consequence the ludicrous situation prevails whereby promotion to full patient responsibility incurs a fall in inoome. I believe it is often helpful when statements such as these are substantiated by hard facts.

A study of the extra-duty returns for this hospital over the past few months shows that some senior house officers are now earning as much as a consultant, and senior registrars are level-pegging with senior medical and administrative staff near the top of their incremental scales. Some juniors, in addition, are in receipt of the $£ 2000$ interest-free loan offered by area health authorities for house purchase, which at the most conservative of interest rates prevailing in the open market is worth an additional £250 per annum. Few would grudge hard-pressed juniors added remuneration for overtime worked and help with the mortgage burden. I would, however, submit most strongly that what is good for the "braves" ought to be good for the "chiefs"-Review Body and contract negotiators please note.

The estimated local extra-duty bill here for the forthooming year will be $£ 145000$, a sum sufficient to pay for 14 consultants of 10 years' standing with $B$ merit awards or the creation of 24 new consultant posts. I fear that should the latter ever be advertised there will be few who can afford to apply.-I am, etc.,

Radcliffe Infirmary

N. E. DUDLEY Oxford

\section{Consultant Contract}

SIR,-The 10-session contract proposed by the B.M.A. carries many advantages for the part-time consultant and few, if any, for his full-time counterpart. The latter, however, are being asked to support this concept in order to preserve the unity of the profession. Mrs. Castle's proposed contract contains obvious disadvantages for the part-time consultant but advantages for the full-timer. The latter are being asked to oppose itagain in order to preserve the unity of the profession.

If the B.M.A. version of the 10-session contract is ultimately accepted the final advantage to the full-time consultant will be minimal unless he has an equal opportunity to undertake private practice, should he so desire. As whole-time pathologists it is with deep concern that we view the manoeuvrings of some part-time clinicians in various parts of the country who have established or are attempting to establish private pathology laboratories, serviced only by technicians, under their cantrol, and not under the control of consultant pathologists.

In return for our suppont for the B.M.A. contract many consultant pathologists may find themselves effectively prevented from undertaking private work to supplement their 10-session incomes. The profession must remain united, but this may not be possible if clinical consultants, while happy to use the services of their colleagues in other specialties for their N.H.S. work, usurp these functions in their private work. -We are, etc.,

W. H. GEORGE
D. GOLDBERG
G. OWBN

G. OWBN

G. W. Pennington P. SEWBLL

Trent Regional Health Authority,

Sheffield

\section{Crisis in the Health Service}

SIR,-Every week a large number of letters on the present crisis in the N.H.S. are published. Inevitably there is one written in similar vein to that of Dr. L. H. Cane (1 February, p. 275).

I thave seen many such over the past few weeks and a large percentage are written by practitioners who qualified before the war. This places them in a category of doctors who have invariably passed the major financial burdens of their lives. If only they could put themselves in the place of a young praotitioner who is trying to buy a house and provide a reasonable standard of living for his wife and growing children in these days of rapid inflation I feel they would be more sympathetic.

The majority of those who are going to send in their undated resignations are not militant and are endeavouring only to create a situation in which they can practise medicine with the maximum benefit to thei patients, and they feel that a fair award for the thours they work is not an unreasonable request.-I am, etc.,

Windsor

D. K. M. Thomas

\section{Dispensing Practices}

SIR,-Dr. F. E. S. Hatfield (1 February, p. 276) suggests that I am muah too kind to the pharmacist in the remarks $I$ made in your interview (11 January, p. 108).

I understand Dr. Hatfield's comment that if the patients' convenience were the only factor to be considered all practices would be dispensing practices, but the present position is more complex. Medical practices and pharmacists' businesses have developed over the course of many years, and their siting, manning, and economios are interconneoted. G.P.s with dispensing practices who have had a pharmacist open in their area know this to their cost. Likewise, some pharmacists have seen a doctor start dispensing in an area previously served by the pharmacist and have suffered a loss. These occurrences have been relatively few, but friction invariably follows between pharmacist and doctor. Our suggestion for a moratorium is to try to remove this source of friction.

One of the major reasons for the deterioration in the normal harmonious relation between pharmacist and doctor is the mistaken belief that dispensing by doctors is increasing. Over the past 10 years the number of dispensing doctors has decreased slightly, but the volume of dispensing by pharmacists has increased from $225 \mathrm{~m}$. to over $300 \mathrm{~m}$. scrips per year in the same period. It is true that there has been a reduction in the number of pharmacies from over 14000 to approximately 11000 , but all the evidence points to a substantial increase in dispensing by pharmacists over the past 10 years. Nevertheless, the small pharmacist is in peril because his costs are rising, because competition is fierce for his counter trade, because his method of remuneration was altered in 1964 in favour of the larger pharmacy, because his contract allows a newcomer ("leap-frogger") to move in nearer to the surgery, because the doctors may move to new premises nearer another pharmacy, and because on retirement there will be no one to buy his business.

I have tried to understand the pharmacists' difficulties, not to be kind but to try to restore good relations between our two professions. The Minister of State, Dr. David Owen, has informed us that there will be no change in the dispensing regulations without agreement between the two professions. Any possible change must surely pass the test of being in the interests of patients and avoiding any arbitrary change in the economics of the pharmacy or dispensing practice, but it is unlikely there will be any agreement unless we can understand each other's difficulties.-I am, etc.,

Michael A. WILSON

Chairman, Rural Practices Subcommittee, B.M.A.

\section{G.P.s' Wives and N.I. Contributions}

SIR,-The B.M.A. points out that a doctor's payment to his wife in excess of $£ 572$ per annum will entail payment of earningsrelated contributions on the whole of her earnings. The B.M.A. goes on to point out that reduction in the amount paid to a wife will result finally in reducing the payment for practice expenses. Surely the answer to this is for us all to engage more secretarial help, for which the N.H.S. will have to pay its $70 \%$, thus robbing Barbara to pay Dennis.

In my view this inclusion of a wife's earnings with her husband's is even more iniquitous than the earnings-related contribution imposed upon the husband himself. I should have thought that in so far as my wife works for me in my practice she is an employed person and that all that should be required in respect of her is that she should pay a married women's contribution. -I am, etc.

Hawkhurst, Kent

C. R. Woop

\section{Limited Membership?}

SIR, - We are not, at present, members of the B.M.A. and it has been represented to us that in these difficult times we should be. We do not feel that we are able to support some of the functions which the B.M.A. supply and we (1) do not require a gentlemen's club in the centre of London, (2) do not require a private car park in the centre of London, and (3) are already members of learned societies providing library and research facilities and journals and do not require these to be duplicated by the B.M.A.

We would, however, be prepared to join immediately for negotiating rights only, now that the B.M.A. is considered to be a trade union, and we would be prepared to pay a reduced fee for this.- We are, etc.,

M. A. WIGGINS B. J. RANSCOMBE Bracknell, Berks 